\title{
Structural and Spectroscopic Characterization of PM 597 Dye-Silica Core-Shell Nanoparticles
}

\author{
Tahani R. Al-Biladi, ${ }^{1}$ A. S. Al Dwayyan, ${ }^{1}$ M. Naziruddin Khan, ${ }^{2}$ \\ Saif M. H. Qaid, ${ }^{1}$ and Khalid Al Zahrani ${ }^{1}$ \\ ${ }^{1}$ Physics and Astronomy Department, College of Science, King Saud University, P.O. Box 2455, Riyadh 114 51, Saudi Arabia \\ ${ }^{2}$ King Abdullah Institute for Nanotechnology, King Saud University, Riyadh 114 51, Saudi Arabia \\ Correspondence should be addressed to M. Naziruddin Khan; mnkhan_phy@yahoo.com
}

Received 4 October 2014; Revised 16 December 2014; Accepted 17 December 2014

Academic Editor: Maria Carmen Yebra-Biurrun

Copyright (C) 2015 Tahani R. Al-Biladi et al. This is an open access article distributed under the Creative Commons Attribution License, which permits unrestricted use, distribution, and reproduction in any medium, provided the original work is properly cited.

\begin{abstract}
Nanostructured fluorescent pyrromethene (PM) doped-silica core-shell particles were successfully prepared by Stöber process. The average size of the particles was in the range of $10-20 \mathrm{~nm}$ measured by TEM micrograph. The atomic structure and morphology of PM 597/ $\mathrm{SiO}_{2}$ core/shell nanoparticles were studied by AFM and SEM, respectively. Absorption and emission spectra of the PM $597 / \mathrm{SiO}_{2}$ core/shell nanoparticles under the UV irradiation were studied and not significantly influenced at the position of peaks. Finally, amplified spontaneous emission (ASE) and photobleaching of dye were examined and found no significant influence on the peaks of PM dye due to the formation of smaller sizes of $\mathrm{PM} 597 / \mathrm{SiO}_{2}$ core/shell nanoparticles. The observed $\mathrm{PM} 597 / \mathrm{SiO}_{2}$ core/shell nanoparticles were different in shapes with smaller size distribution and highly luminescent. Majority of nanoparticles were roughly spherical with many of them aggregated. The less photobleaching of dye core may be due to the protection of pumped energy by $\mathrm{SiO}_{2}$ shell and restricts the leakage of dye.
\end{abstract}

\section{Introduction}

Preparation and analysis of fluorescent dye nanoparticles for the application of biotechnology $[1,2]$ and information technology applications such as biological imaging, sensor technology, microarrays, and optical computing [36] have been studied. Nanoparticles are intermediate state between molecular and bulky forms of material and also can provide unique chemical, optical, and electronic properties by combining their surface modification and composition control [7]. Studies revealed that various kinds of organic dyes are currently used in biolabeling, but they are not photostable and often suffer from photobleaching [8]. Studies have been reported to overcome photobleaching effect and enhance radiation properties including the use of quantum dot nanocrystal [9], dye doped-silica [10], and core-shell structure of dye-silica [11]. In fact, sol-gel derived silica is considered an excellent host material for creating fluorescent nanoparticles by the inclusion of covalently bound organic dyes. Significant enhancements in the brightness with chemical stability of dye emission can be achieved and architecture at the length of scales down to tens of nanometers with narrows size distributions [12]. Moreover, core-shell structure of dye-silica can be substituent for fluorescent dye because silica surface can be modified to various functional groups and enhances the thermal and chemical stability of the nanoparticles with less oxidation and cytotoxicity [13]. In view of importance of the above, improvement of photostability of dye-silica core-shell nanoparticles is still interesting for the potential applications of solid state dyes laser [14] and as a biological marker [15, 16]. Therefore, a detailed study of 597 pyrromethene dye-silica core-shell nanoparticles was performed using structural and optical techniques. The main aim of this work is to investigate the optical stability, ASE of PM597-core silica shell, since the PM dye has unique chemical structure and is highly luminescent. 


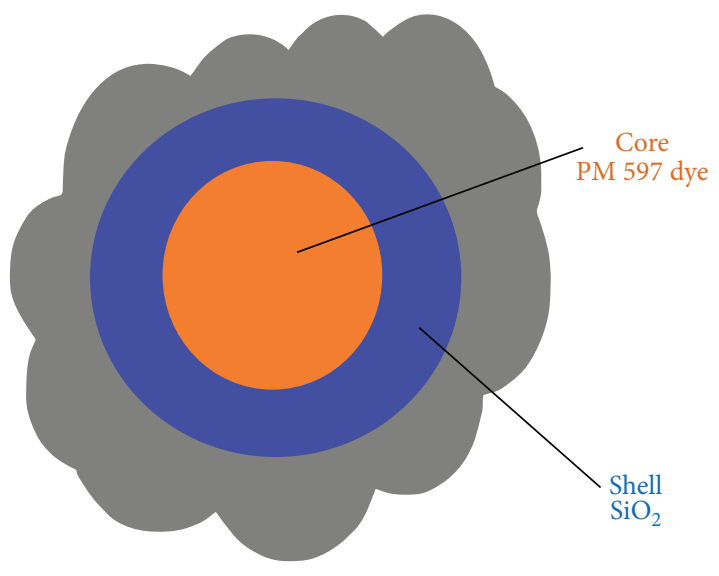

FIGURE 1: Schematic nanostructure of PM dye/ $/ \mathrm{SiO}_{2}$ core-shell NPs.

\section{Experimental Details}

Commercially obtained pyrromethene (PM) 597 dye (SigmaAldrich) was used to prepare the dye doped core-shell nanoparticles using the Stöber sol-gel process [17, 18]. The detail of materials preparation was described elsewhere [12, 19]. Shortly, the Stöber process involves the hydrolysis and polycondensation of tetraethyl orthosilicate (TEOS) in water and ethanol solutions. Tetraethyl orthosilicate was used as the precursor to synthesis of silica core having the general molecular formula as

$$
\begin{gathered}
\mathrm{OC}_{2} \mathrm{H}_{5} \\
\mathrm{H}_{5} \mathrm{C}_{2} \mathrm{O}-\mathrm{Si}-\mathrm{OC}_{2} \mathrm{H}_{5} \\
\text { । } \\
\mathrm{OC}_{2} \mathrm{H}_{5}
\end{gathered}
$$

In the process, a weighed PM dye was dissolved in ethanol and stirred for about 10 minutes until solution became homogenous. 3-Mercaptopropylsilane was then added to the above dissolved solution in order to promote covalent bonding of the dye molecules into the silica particles. The mixture was stirred in a glass vessel for 12 hours under nitrogen atmosphere to prevent oxidation and also kept in dark to prevent dye bleaching. The preparation was followed by adding additional amount of ethanol, water, ammonium hydroxide as a catalyst, and TEOS as a silica precursor which was gradually added: $0.5 \mathrm{~mL}$ per 10 minutes. The final mixture was further stirred to become completely homogeneous. The process was performed at room temperature.

The schematic structure of nanostructured PM dye/coreshell is shown in Figure 1. The particles size and structural analysis of the PM $597 / \mathrm{SiO}_{2}$ core/shell nanoparticles were studied by FETEM (JEOL-2100F) and FESEM (JEOL, JSM$7600 \mathrm{~F})$, respectively. The surface atomic structure of the synthesized DSCSNPs was also characterized using AFM (Veeco multimode V Scan Probe Microscope).

Absorption spectra of the PM $597 / \mathrm{SiO}_{2}$ core/shell nanoparticles were collected in $200-800 \mathrm{~nm}$ spectral range using a double beam UV-visible spectrophotometer (PerkinElmer Lambda-40) with a resolution of $0.5 \mathrm{~nm}$. Photoluminescence spectra were recorded with a luminescence spectrometer (Perkin-Elmer LS 45) at spectral resolution of

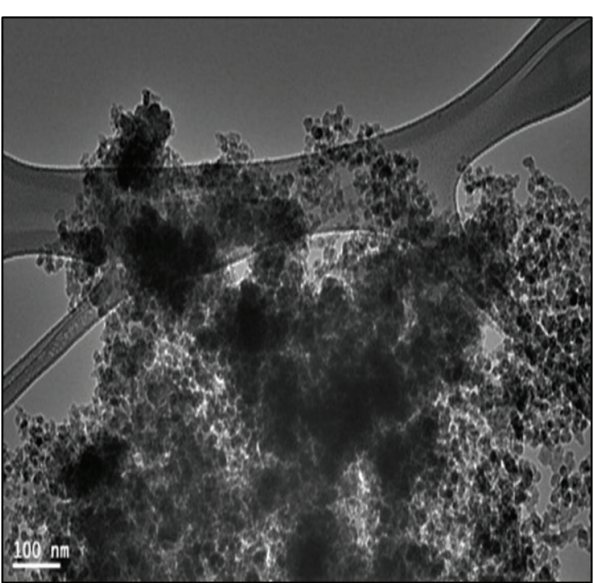

(a)

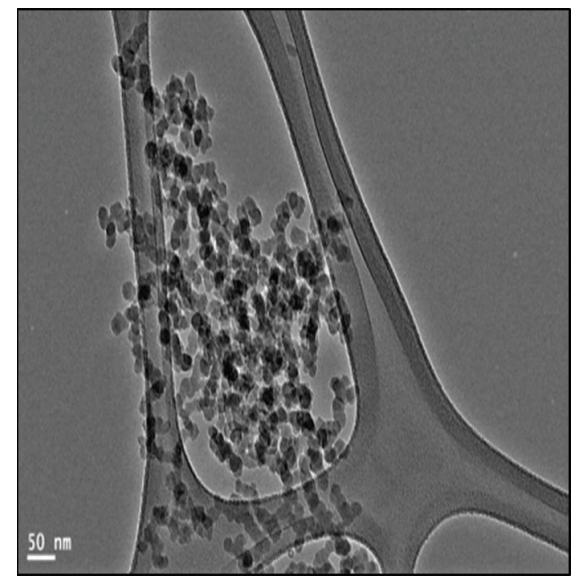

(b)

Figure 2: The TEM images of $\mathrm{PM} 597 / \mathrm{SiO}_{2}$ core/shell NPs at different scale.

$0.5 \mathrm{~nm}$. The photoluminescence of pure dye and dye dopedsilica particles was checked in solid powder form as well as in solid powder dispersed in ethanol. Excitation and emission spectra were measured over a wavelength range of 200$700 \mathrm{~nm}$. Finally, photostability of the dye and $\mathrm{PM} 597 / \mathrm{SiO}_{2}$ core/shell nanoparticles samples was studied using Nd:YAG pulse laser with the energy of $15 \mathrm{~m}$ ), Solar, LPS $1500(\lambda=$ $532 \mathrm{~nm}$ ) as pump source.

\section{Results and Discussion}

The distribution and size of nanostructure dye-silica coreshell particles were investigated by TEM micrograph at different scale as shown in Figure 2. As seen in TEM images, dye-core shell particles are well distributed and aggregated with sizes of about $10-20 \mathrm{~nm}$. For particular dye, the particles size distribution differs depending on the dye structure as our previous result reported [12]. The figure shows the nanoparticles are approximately homogenous and circular with the existence of shell outside the core. Although there are no observed clear core and shell, some particles with cores as dark spot and others inside shell are seen. The average diameter of the obtained $\mathrm{PM} 597 / \mathrm{SiO}_{2}$ core/shell 


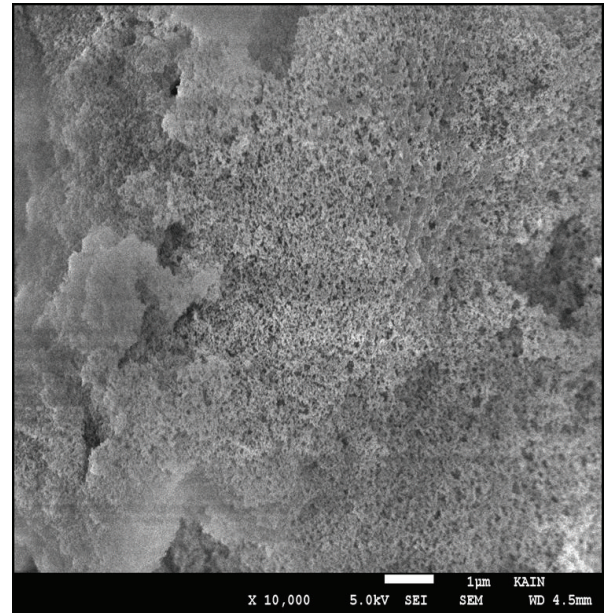

Figure 3: FE-SEM image of PM 597/SiO 2 core/shell NPs.

nanoparticles was also measured using a light scattering particle size analyzer and found to be about $90 \mathrm{~nm}$. The difference in particle sizes of TEM image and scattering may be a reason that there are aggregated particles which lead to increasing size particle. Figure 3 shows SEM image of PM $597 / \mathrm{SiO}_{2}$ core/shell nanoparticles. Particles can be seen with many roughly circular dark spot in the environment of $\mathrm{SiO}_{2}$. In order to understand the topographical of the synthesized PM 597/ $/ \mathrm{SiO}_{2}$ core/shell nanoparticles, AFM images were taken in contact and taping mode is shown in Figure 4. The color gradient indicates the different height with size of the particles and assembles into coarse aggregate forming piles. The individual particles show almost the same height at approximately $15 \mathrm{~nm}$, although the particles diameter differs, ranging from $25 \mathrm{~nm}$ to more than $200 \mathrm{~nm}$. Such a difference between the particle diameter and its height may impart nonspherical shape to the particle. However, the distinct rim surrounding the particles is shown in Figure 4 (insect (B), (C)). Here we concern height of individual particles, not other aggregated large particles. It is very difficult to take the height of larger particles because of some particles inside gel.

\section{Absorption and Fluorescence Spectra}

The UV-Vis absorption and fluorescence spectra of the pure PM dye and prepared PM 597/ $\mathrm{SiO}_{2}$ core/shell nanoparticles were measured in ethanol within the $200-800 \mathrm{~nm}$ region. The basic properties of PM dye are listed in Table 1. Comparison between the absorption and emission peak positions of the pure PM dye and dye-silica core-shell NPs before and after UV irradiation is shown in Figure 5. The absorption and emission peaks of PM dye do not affect the corresponding peaks of $\mathrm{PM} 597 / \mathrm{SiO}_{2}$ core/shell nanoparticles. The corresponding absorption and emission peaks lie at $524 \mathrm{~nm}$ and $562 \mathrm{~nm}$ of both samples, respectively. A mall blue shift in the emission spectra of PM 597/ $\mathrm{SiO}_{2}$ core/shell nanoparticles is observed about $3 \mathrm{~nm}$ which might be related to the site effect due to interaction of dye molecules with the silica. But the corresponding intensity of $\mathrm{PM} 597 / \mathrm{SiO}_{2}$ core/shell nanoparticles in absorption and emission is significantly improved
TABle 1: Basic information of Pyrromethene 597 dye taken from [20].

Dye
Chemical formula
Molecular weight $(\mathrm{g} / \mathrm{mol})$

from the intensity of PM dye. It is assumed that the increase in emission intensity may be in accordance with the decrease in the nonradiative because of rate of less dissociation of dye from smaller sizes core-shell nanoparticles.

It may be mentioned that organic dyes are considered optically unstable when subjected to UV light because of the molecular bonding dissociation (photobleaching). In order to clear and understand the optical stability, the dye-silica core nanoparticles were exposed to UV radiation for 4 hours under a conventional UV lamp. Absorption and emission spectra were recorded before and after UV irradiation for PM 597/ $/ \mathrm{SiO}_{2}$ core/shell nanoparticles and PM dye. There is no significant change in absorption and emission peaks of PM 597/ $\mathrm{SiO}_{2}$ core/shell nanoparticles after UV exposure as shown in Figure 5. A small reduction in the absorbance and emission of PM dye after UV irradiation can be noticed while no effect in the PM 597/ $\mathrm{SiO}_{2}$ core/shell nanoparticles is observed. Such small decay in PM dye could correspond to the photobleaching due to molecular dissociation during UV exposure. It is also possible that due to change in outer surface of shell under UV, absorption and emission peak of PM dye are increased.

The existence of optically stable PM 597/ $\mathrm{SiO}_{2}$ core/shell nanoparticles under UV exposure is evident which may be a result of the presence of dye molecules in core-shell particles when the dye is protected inside the silica shell leading to an increase in the absorption and emission [12, 13]. Emission peak of PM 597 dye is slightly blue shifted from $563 \mathrm{~nm}$ to $561 \mathrm{~nm}$ with intensity increment by $21.51 \%$. This means that the UV light affects the dye molecules while PM 597/ $/ \mathrm{SiO}_{2}$ core/shell NPs showed stable behavior with $2.16 \%$ intensity increase factor.

Stokes shifts were calculated from absorption and fluorescence spectra with using the relation

$$
\text { Stokes shift }=\left[\frac{1}{\lambda_{\mathrm{abs}}(\mathrm{nm})}-\frac{1}{\lambda_{\mathrm{em}}(\mathrm{nm})}\right] * 10^{7}(\mathrm{~nm} / \mathrm{cm}) \text {. }
$$

Figure 5 illustrates Stokes shifts of PM 597 dye and PM 597/ $/ \mathrm{SiO}_{2}$ core/shell NPs. Stokes shifts of PM 597 dye equal $39 \mathrm{~nm}$ while those of $\mathrm{PM} 597 / \mathrm{SiO}_{2}$ core/shell NPs 

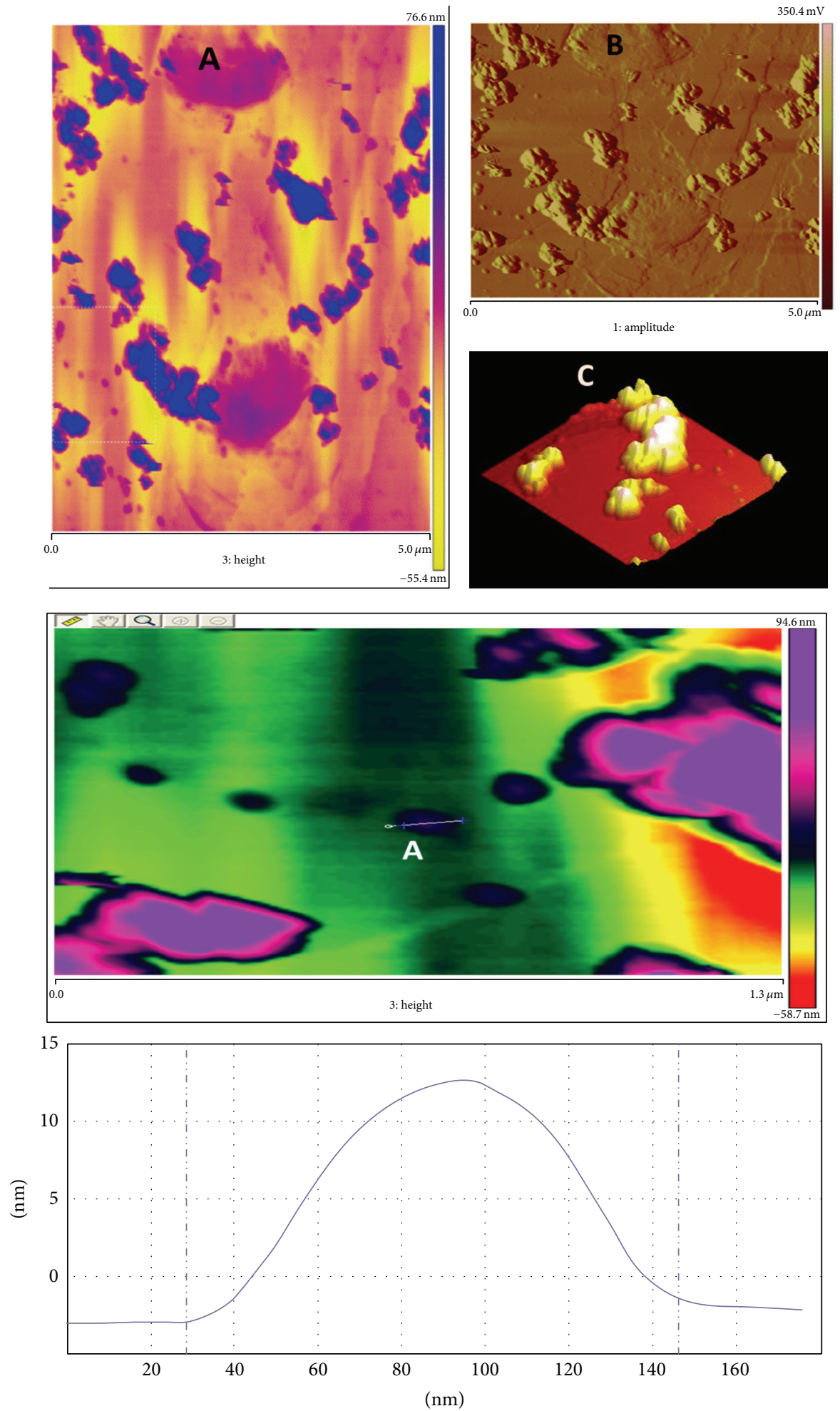

FIGURE 4: AFM height (contact) image (A) and amplitude (tapping) (B) of PM 570/SiO 2 CANPs (scan size is $5 \mu \mathrm{m}$ ) showing scattered particles with diameter ranging from $25 \mathrm{~nm}$ to approximately $200 \mathrm{~nm}$ and isolated islands of particles cluster with different sizes. 3D image (C) is a magnified image of the area outlined by a dashed square in (A). Obvious rims around the particles indicate that the particles are embedded in the gel. The height of the particle is shown with scale bar. 


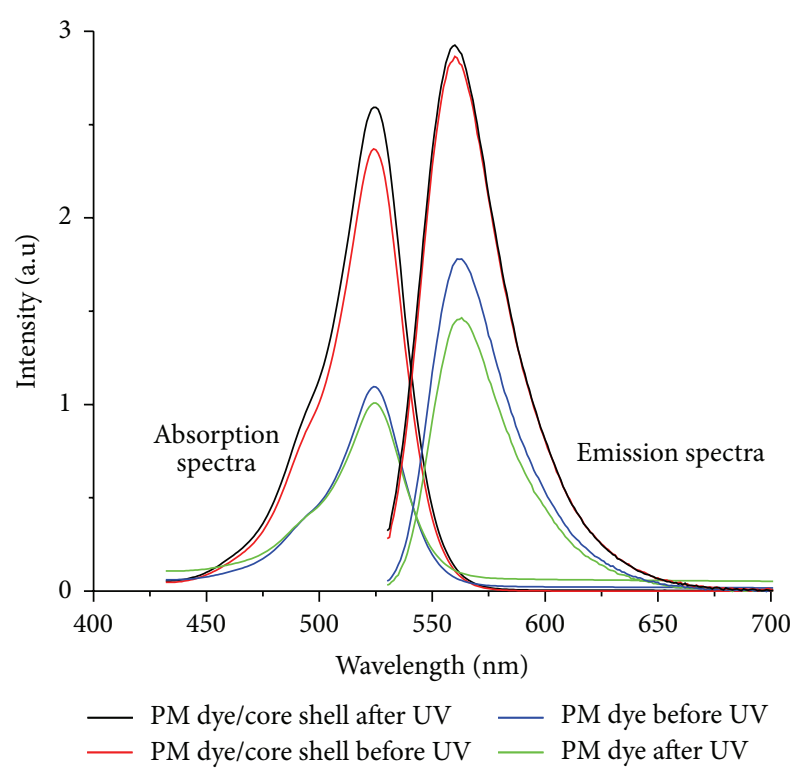

FIGURE 5: Comparison of absorption and emission spectra of PM597 dye and PM 597/ $/ \mathrm{SiO}_{2}$ core/shell NPs before and after UV irradiation.

equal $36 \mathrm{~nm}$. Obviously, Stokes shift of PM 597 dye is larger than PM 597 dye/core-shell nanoparticles due to the more scattering light from dye.

Stokes shifts of PM 597 dye are as follows:

$$
\left[\frac{1}{524(\mathrm{~nm})}-\frac{1}{563(\mathrm{~nm})}\right] * 10^{7} \mathrm{~nm} / \mathrm{cm}=1321.98 \mathrm{~cm}^{-1} \text {. }
$$

Stokes shift of PM 597/ $\mathrm{SiO}_{2}$ core/shell NPs is as follows:

$$
\left[\frac{1}{524(\mathrm{~nm})}-\frac{1}{560(\mathrm{~nm})}\right] * 10^{7} \mathrm{~nm} / \mathrm{cm}=1226.82 \mathrm{~cm}^{-1} .
$$

4.1. Photostability of PM Dye and PM 597/SiO 2 Core/Shell Nanoparticles under Laser Source. Although high efficiencies were reported for some fluorescent laser dyes, photodegradation of the dyes caused by pump energy or high repetition rate pumping light pulses is still unsolved. To improve the photostability of an organic dye, additives to the host composition were the alternative means to prevent photooxidation, dissociation, substitution oxidation, and hydrogen abstraction of the dye that can lead to more stable chemical (acid/base) environment [14, 21-23]. In this regard, shielding dye molecules by $\mathrm{SiO}_{2}$ was obtained to be optically stable [12].

In this work optical stability of PM 597 dye and PM $597 / \mathrm{SiO}_{2}$ core/shell nanoparticles was examined under continuous intense laser beam for three hours. The pumped laser source was performed by 2 nd harmonics of Nd:YAG laser $(532 \mathrm{~nm})$ at $15 \mathrm{~mJ}$. The fluorescence intensity of samples was recorded every ten minutes during laser exposure.

Figure 7 shows the response of fluorescence intensity versus time of $\mathrm{PM} 597$ and $\mathrm{PM} 597 / \mathrm{SiO}_{2}$ core/shell NPs

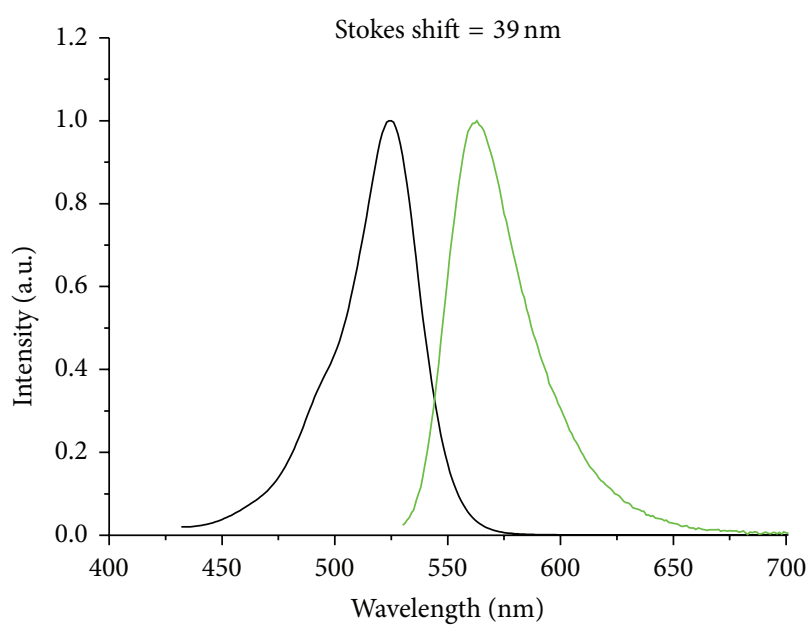

PM 597 free dye

- Absorption

— Fluorescence

(a)

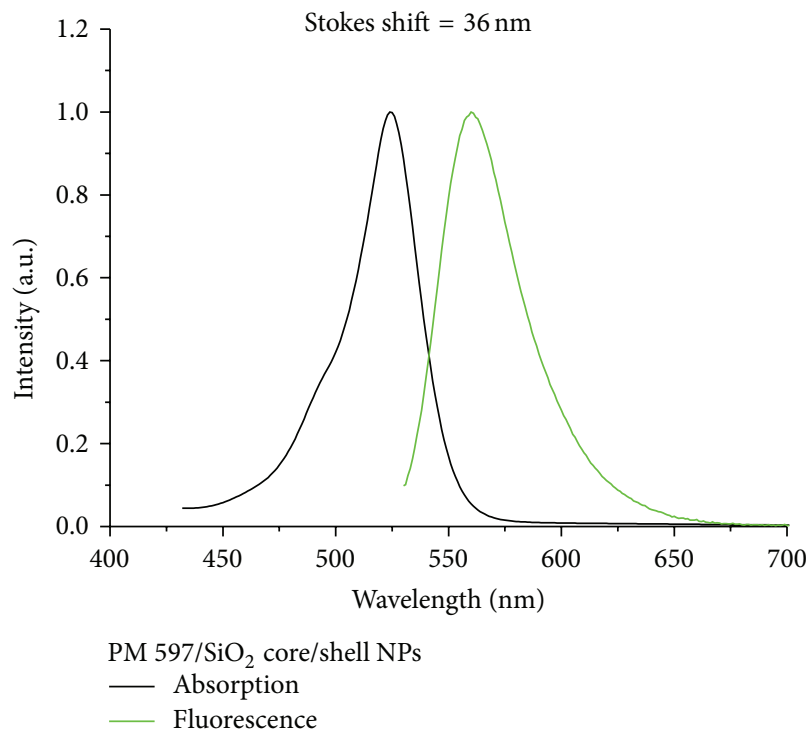

(b)

Figure 6: Stokes shifts of (a) PM 597 dye and (b) PM 597/SiO core/shell nanoparticles.

during sixty minutes. As clearly seen in Figure 6, the emission intensity of due-silica core-shell NPs is approximately linear up to 30 min while the intensity for PM597 dye shows nonlinear behavior under laser light. The intensity slightly starts to drop after $60 \mathrm{~min}$. The emission intensity of PM dye/silicacore under the laser excitation is not significantly influenced up to 30 minutes and then starts to drop continuously till 60 min but the emission intensity of PM dye continually decays against laser energy. But our group observed the stable behavior of $\mathrm{R} 6 \mathrm{G} / \mathrm{SiO}_{2}$ core/shell NPs sample when pumped with high laser source for the first 60 minutes [12]. This means that dye doped-silica core nanoparticles are protected from photobleaching where the laser energy is incident on the site of sample. 


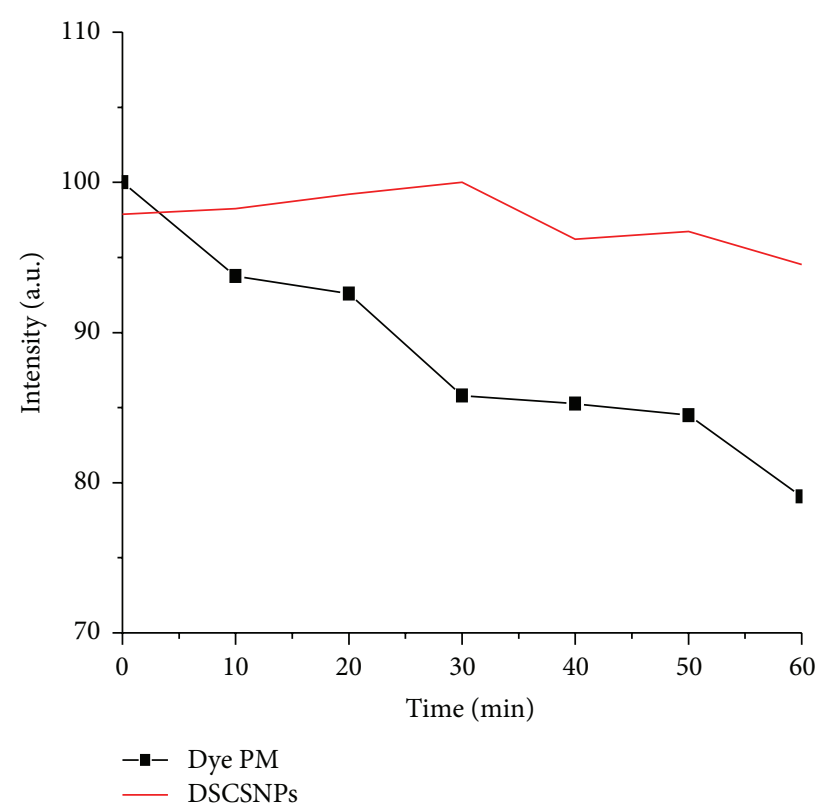

FIgURE 7: Emission stability of PM597 dye and PM 597/SiO 2 core/shell NPs under pulsed laser excitation during 60 minutes.

4.2. Amplified Spontaneous Emission (ASE). ASE of dye-core silica shell nanoparticles was examined under the $532 \mathrm{~nm}$ excitation source of Nd:YAG laser system. The response emitted light from the $\mathrm{PM} / \mathrm{SiO}_{2}$ core/shell nanoparticles is observed as a narrow line width about $4 \mathrm{~nm}$ as seen in Figure 8. Such a narrow line width indicates that PM dye-core shell particles may be suitable as gain media if the samples could make proper solid composites. In this direction, work is underway to realize the optical gain from $\mathrm{PM} / \mathrm{SiO}_{2}$ core/shell nanoparticles solid composites.

\section{Conclusion}

Pyrromethene dye molecules were successfully entrapped as cores in silica shell with various sizes. PM 597/ $\mathrm{SiO}_{2}$ core/shell NPs with thick silica shells could be obtained without affecting the integrity of the cores. Synthesized PM 597/ $\mathrm{SiO}_{2}$ core/shell NPs are observed to be monodisperse, homogenous with being circular in shapes. $\mathrm{PM} / \mathrm{SiO}_{2}$ core/shell nanoparticles are found to be good in stability under UV exposure. Photoluminescence of these core-shell particles is exhibited to be highly luminescent. Thus, the dye is significantly stable inside the silica particles and can be used without change of luminescence wavelength. UV irradiation experiment of dye entrapped core-shell particles does not show photobleaching which is observed in case of dyes. A narrow bandwidth of $\mathrm{PM} / \mathrm{SiO}_{2}$ core/shell nanoparticles is obtained under optical cavity pumped by laser source.

\section{Conflict of Interests}

The authors declare that there is no conflict of interests regarding the publication of this paper.

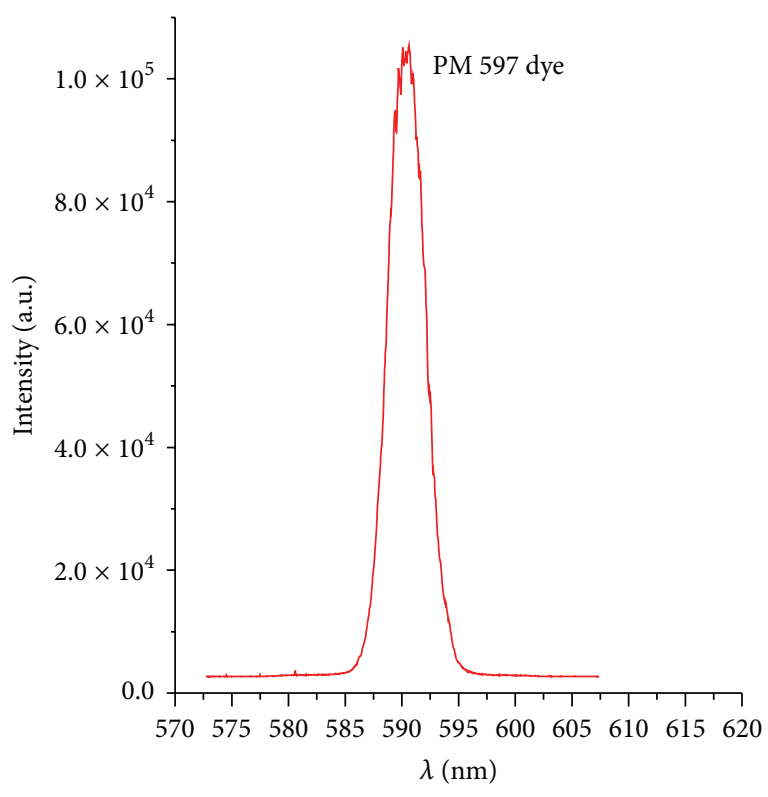

(a)

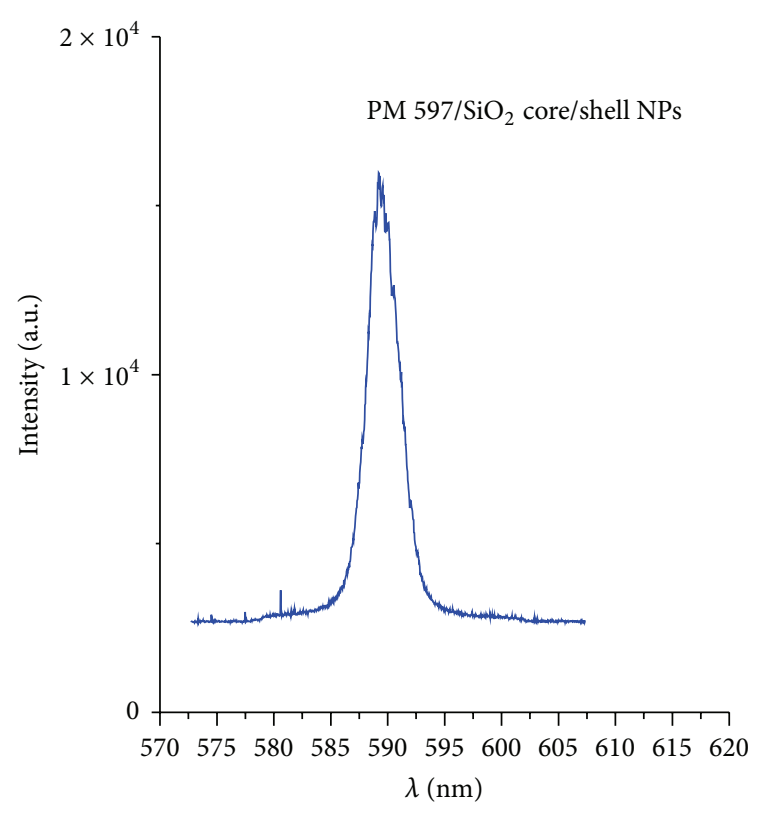

(b)

FIgURE 8: ASE of PM 597 dye and PM 597/SiO 2 core/shell NPs.

\section{Acknowledgment}

This project was supported by Deanship of Scientific Research, College of Science Research Center, King Saud University.

\section{References}

[1] J. K. Jaiswal, H. Mattoussi, J. M. Mauro, and S. M. Simon, "Longterm multiple color imaging of live cells using quantum dot bioconjugates," Nature Biotechnology, vol. 21, no. 1, pp. 47-51, 2003. 
[2] E. R. Goldman, A. R. Clapp, G. P. Anderson et al., "Multiplexed Toxin Analysis Using Four Colors of Quantum Dot Fluororeagents," Analytical Chemistry, vol. 76, no. 3, pp. 684-688, 2004.

[3] W. C. W. Chan and S. Nie, "Quantum dot bioconjugates for ultrasensitive nonisotopic detection," Science, vol. 281, no. 5385, pp. 2016-2018, 1998.

[4] J. B. Jackson and N. J. Halas, "Silver nanoshells: variations in morphologies and optical properties," The Journal of Physical Chemistry B, vol. 105, no. 14, pp. 2743-2746, 2001.

[5] S. Lal, R. N. Taylor, J. B. Jackson, S. L. Westcott, P. Nordlander, and N. J. Halas, "Light interaction between gold nanoshells plasmon resonance and planar optical waveguides," The Journal of Physical Chemistry B, vol. 106, no. 22, pp. 5609-5612, 2002.

[6] J. B. Jackson, S. L. Westcott, L. R. Hirsch, J. L. West, and N. J. Halas, "Controlling the surface enhanced Raman effect via the nanoshell geometry," Applied Physics Letters, vol. 82, no. 2, pp. 257-259, 2003.

[7] D. Y. Godovsky, "Device applications of polymer-nanocomposites," in Biopolymers. PVA Hydrogels, Anionic Polymerisation Nanocomposites, vol. 153 of Advances in Polymer Science, pp. 163-205, Springer, Berlin, Germany, 2000.

[8] F. Kulzer, S. Kummer, R. Matzke, C. Bräuchle, and T. Basché, "Single-molecule optical switching of terrylene in p-terphenyl," Nature, vol. 387, no. 6634, pp. 688-691, 1997.

[9] W. J. Parak, T. Pellegrino, and C. Plank, "Labelling of cells with quantum dots," Nanotechnology, vol. 16, no. 2, pp. R9-R25, 2005.

[10] C. Graf, W. Schärtl, K. Fischer, N. Hugenberg, and M. Schmidt, "Dye-labeled poly(organosiloxane) microgels with core-shell architecture," Langmuir, vol. 15, no. 19, pp. 6170-6180, 1999.

[11] H. Ow, D. R. Larson, M. Srivastava, B. A. Baird, W. W. Webb, and U. Wiesnert, "Bright and stable core-shell fluorescent silica nanoparticles," Nano Letters, vol. 5, no. 1, pp. 113-117, 2005.

[12] A. S. Al Dwayyan, S. M. H. Qaid, M. A. Majeed Khan, and M. S. Al Salhi, "Structural and spectral investigations of Rhodamine (Rh6G) dye-silica core-shell nanoparticles," Optical Materials, vol. 34, no. 5, pp. 761-768, 2012.

[13] H.-H. Yang, H.-Y. Qu, P. Lin, S.-H. Li, M.-T. Ding, and J.-G. Xu, "Nanometer fluorescent hybrid silica particle as ultrasensitive and photostable biological labels," Analyst, vol. 128, no. 5, pp. 462-466, 2003.

[14] M. Naziruddin Khan and A. S. Al Dwayyan, "Influence of solvent on the physical and lasing properties of dye-doped solgel host," Journal of Luminescence, vol. 128, no. 11, pp. 1767-1770, 2008.

[15] J. E. Fuller, G. T. Zugates, L. S. Ferreira et al., "Intracellular delivery of core-shell fluorescent silica nanoparticles," Biomaterials, vol. 29 , no. 10, pp. 1526-1532, 2008.

[16] D. Ma, A. J. Kell, S. Tan, Z. J. Jakubek, and B. Simard, "Photophysical properties of dye-doped silica nanoparticles bearing different types of dye-silica interactions," Journal of Physical Chemistry C, vol. 113, no. 36, pp. 15974-15981, 2009.

[17] W. Stöber, A. Fink, and E. Bohn, "Controlled growth of monodisperse silica spheres in the micron size range," Journal of Colloid and Interface Science, vol. 26, no. 1, pp. 62-69, 1968.

[18] Y. J. Na, S. J. Park, J. H. Kim, and J. S. Kim, “The preparation of fluorescent nano dye-silica particles by sol-gel process," in Advances in Nanomaterials and Processing, p. 651, 2007.

[19] X.-D. Wang, Z.-X. Shen, T. Sang et al., "Preparation of spherical silica particles by Stöber process with high concentration of tetra-ethyl-orthosilicate," Journal of Colloid and Interface Science, vol. 341, no. 1, pp. 23-29, 2010.
[20] R. Jakubiak, L. V. Natarajan, V. Tondiglia et al., "Electrically switchable lasing from pyrromethene 597 embedded holographic-polymer dispersed liquid crystals," Applied Physics Letters, vol. 85, no. 25, pp. 6095-6097, 2004.

[21] T. I. Suratwala, K. Davidson, Z. Gardlund, D. R. Uhlmann, S. I. Bonilla, and N. Peyghambarian, "Molecular engineering and photostability of laser dyes within sol-gel hosts," in Solid State Lasers VI, Proceedings of SPIE, International Society for Optics and Photonics, San Jose, Calif, USA, March 1997.

[22] A. Al Dwayyan, M. N. Khan, and A. Ghamdi, "Effect of DCCA on the optical and lasing properties of dye doped Silica gels/ORMOSILs," Canadian Journal of Pure \& Applied Sciences, vol. 2, no. 1, p. 221, 2008.

[23] T. I. Suratwala, Photostability of Laser Dyes in Sol-Gel-Derived Hosts, The University of Arizona, 1996. 

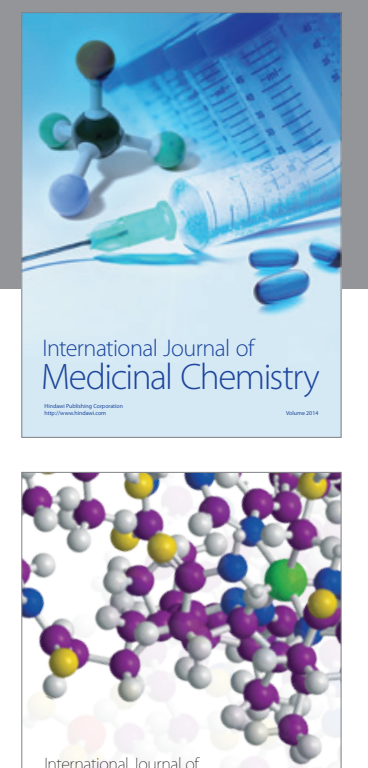

\section{Carbohydrate} Chemistry

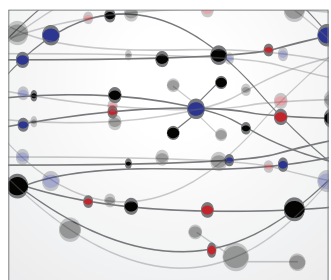

The Scientific World Journal
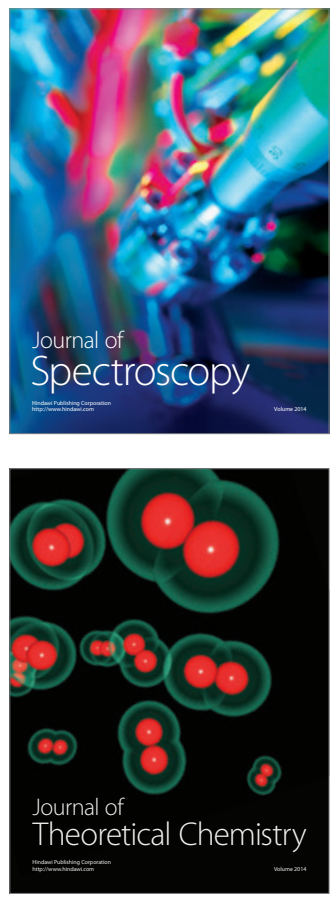
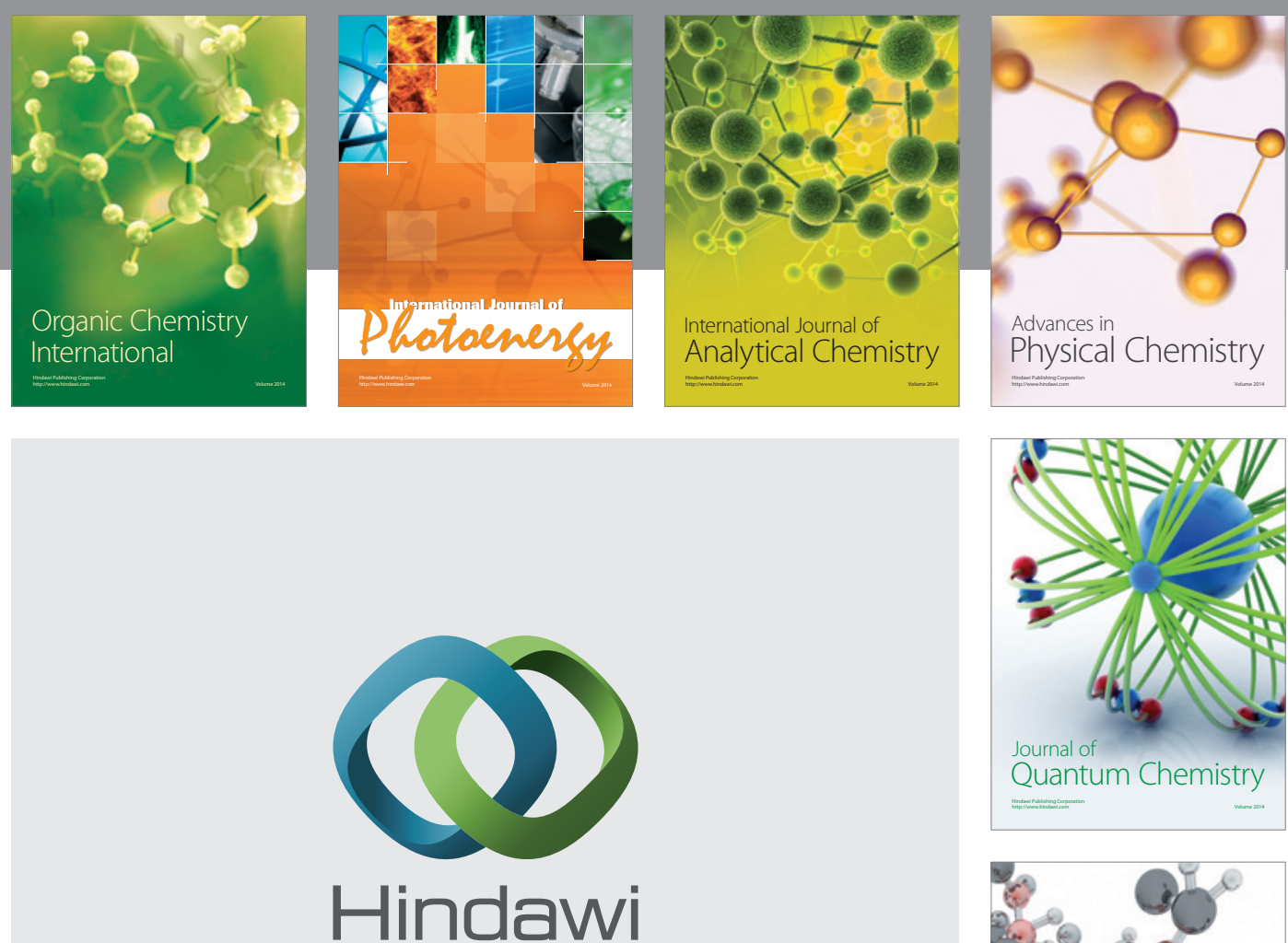

Submit your manuscripts at

http://www.hindawi.com

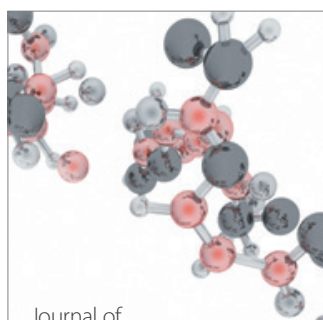

Analytical Methods

in Chemistry

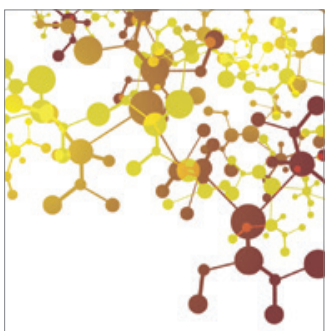

Journal of

Applied Chemistry

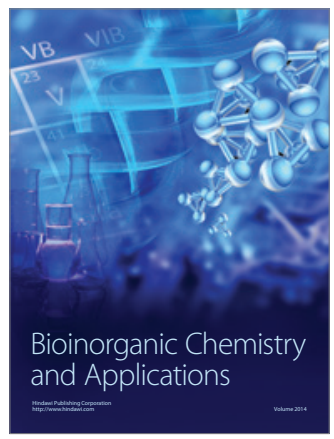

Inorganic Chemistry
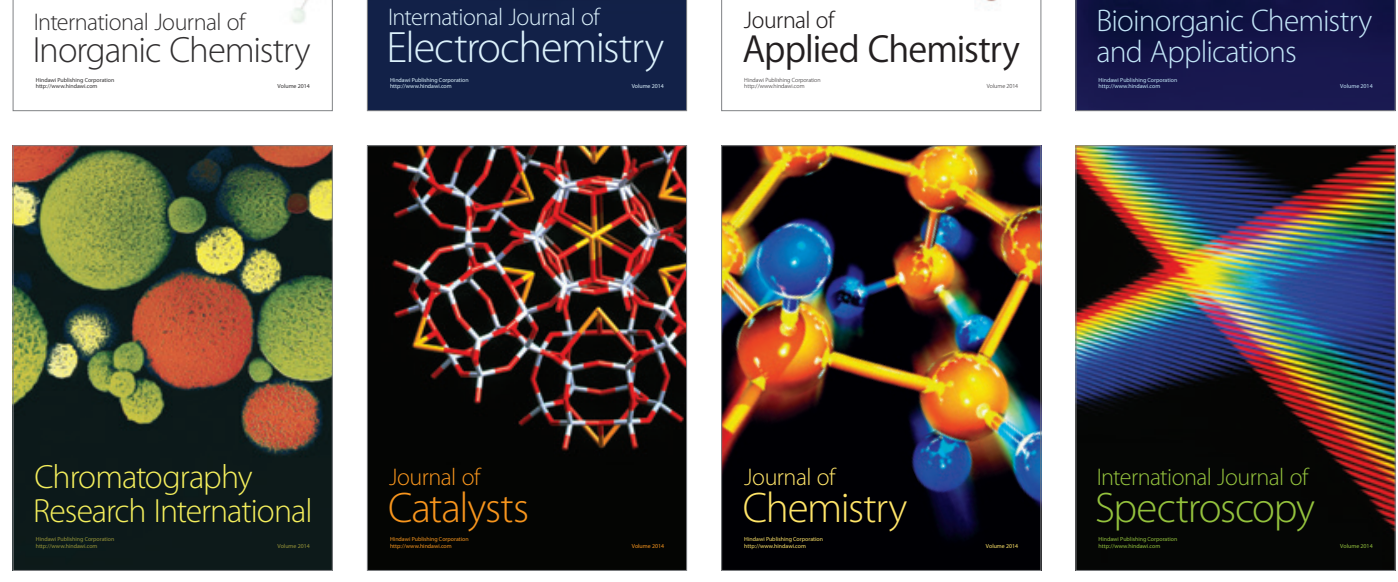